\title{
Intake safety of Lactobacillus helveticus SBT2171 and its effects on nasal and ocular symptoms associated with mites and house dust: An open-label study and a randomized, double-blind, placebo-controlled, parallel group study
}

\author{
Maya Yamashita1, Eiji Kobatake ${ }^{1}$, Shun Obuchi', Masayuki Iwai ${ }^{1}$, Kazuyuki Ichikawa ${ }^{2}$, \\ Toshihide Kabuki ${ }^{1 *}$, Tadao Enomoto ${ }^{3}$
}

${ }^{1}$ Milk Science Research Institute and ${ }^{2}$ Products Development Department, Megmilk Snow Brand Co. Ltd., 1-1-2, Minamidai, Kawagoe, Saitama, 350-1165, Japan; ${ }^{3}$ NPO Japan Health Promotion Supporting Network, 3-68, Komatsubaradoori, Wakayama, Wakayama, 640-8269, Japan.

Corresponding author: Toshihide Kabuki, PhD, Milk Science Research Institute, Megmilk Snow Brand Co. Ltd., 1-1-2, Minamidai, Kawagoe, Saitama, 350-1165, Japan.

Submission Date: September $13^{\text {th }}, 2018$, Acceptance Date: December $28^{\text {th }}, 2018$, Publication Date: January $30^{\text {th }}, 2019$

Citation: Yamashita M., Kobatake E., Obuchi S., Iwai M., Ichikawa K., Kabuki T., Enomoto T. Intake safety of Lactobacillus helveticus SBT2171 and its effects on nasal and ocular symptoms associated with mites and house dust: An open-label study and a randomized, double-blind, placebo-controlled, parallel group study. Functional Foods in Health and Disease 2019; 9(1): 52-78. DOI: https://doi.org/10.31989/ffhd.v9i1.557

\footnotetext{
ABSTRACT

Background: We previously reported that Lactobacillus helveticus SBT2171 (LH2171) inhibited the proliferation and secretion of lipopolysaccharide-stimulated inflammatory cytokines in primary immune cells. Furthermore, in vivo administration of LH2171 has been demonstrated to suppress the incidence and development of murine rheumatoid arthritis. This study aimed to evaluate whether the intake of drinkable yogurt (DY) containing LH2171 alleviated nasal and ocular symptoms of allergy to mites and house dust allergens. The safety of LH2171 was also confirmed in an independent, open-label study in 20 healthy subjects who consumed an excessive amount of LH2171.
} 
Methods: In study 1, the effect of daily intake of DY containing LH2171 for 12 weeks on nasal and ocular symptoms was evaluated in healthy men and women who tested positive for house dust or mite-specific IgE in a randomized, double-blind, placebo-controlled, parallel group study. One hundred subjects were divided into two groups: subjects taking placebo DY (P group, $n=$ 50) and subjects taking DY containing approximately $1 \times 10^{9}$ cells of LH2171 (LH2171 group, $n$ = 50) daily for the 12 weeks. After excluding subjects that met exclusion criteria, data obtained from 94 subjects (LH2171 group: $n=48$; P group: $n=46$ ) were analyzed to establish LH2171 efficacy. LH2171 safety was assessed in an independent, open-label trial in 20 subjects (study 2) who consumed an excessive amount of DY containing approximately $3 \times 10^{9}$ LH2171 cells.

Results: In study 1, the decreases in the total scores of the nasal and ocular discomfort between week 0 and week 8 in LH2171 group were significantly larger than those in P group. Additionally, the number of sneezes decreased significantly in LH2171 group compared with P group on weeks 9-12 compared to the number of sneezes at baseline. In study 2, no adverse effects of LH2171 on systolic bold pressure, diastolic blood pressure, pulse rate, body weight, blood and urinalysis parameters were reported.

Conclusion: Daily intake of LH2171 for 12 weeks may regulate immune function and improve nasal and ocular symptoms in the subjects with mite or house dust allergy.

Keywords: Lactobacillus helveticus SBT2171, nasal and ocular symptoms, IgE antibodies

Clinical trial registration: UMIN000027791 (study 1), UMIN000029058 (study 2).

\section{BACKGROUND}

The prevalence of allergic disease increased dramatically in Japan over the past few decades. According to a patient survey conducted by the Ministry of Health, Labour and Welfare the number of patients with allergic rhinitis increased by about 1.3-fold in 2008 in comparison with that in 1998 [1]. According to the "hygiene hypothesis" originally described by Strachan [2], the increased incidence of allergy is due to reduced exposure to microbial stimulation in early life, which programs the immune system toward the Th2-type allergic response. The reaction of the host to the microorganisms is likely a key process in the onset of allergy. The major allergens are seasonal pollens, such as cedar and cypress and perennial house dust [3]. House dust or indoor 
dust is a mixture of mites, ticks, human scraps (dandruff), mold, mites, and bacteria. In particular, house dust mites are the most common allergen source in humid areas, such as coastal cities and towns [4]. The main species of house dust mites are the members of the Drosophilidae family Dermatophagoides farinae and D. pteronyssinus, which are common worldwide. Mite content over $2 \mu \mathrm{g}$ per $1 \mathrm{~g}$ of house dust has been reported to increase the risk of allergic rhinitis [5].

Allergic symptoms manifest not only as runny nose and sneezing but also ocular symptoms, such as itching eyes and eye swelling, which affects wellbeing. As there is currently no way to cure allergies completely, the elimination or avoidance of causative substances (pollen, ticks, house dust, etc.) is recommended to alleviate allergic symptoms as well as taking drugs for symptomatic therapy. The ultimate goal of the anti-allergic treatment is to relieve symptoms and improve daily quality of life (QOL).

The major mechanism of the allergic response is Th2 cytokine secretion, which induces the production of IgE antibodies by B cells. Activation of Th2 response leads to the secretion of interleukin (IL)-4, IL-5, and IL-13 and the production of allergen-specific IgE $[6,7]$. When the subjects are exposed to the allergens allergic reactions are induced. Given that the use of drugs such as steroids, antihistamines, and others does not always bring relief, the prevention of allergy development becomes more important than pharmacological treatment.

Lactic acid bacteria (LAB) has been recently reported to have beneficial effects on human health, not only by improving the environment of the intestine but also by influencing immune functions $[8,9]$. Prevention and treatment of allergies by the administration of probiotics such as LAB and bifidobacteria have been described. Indeed, the beneficial effects of LAB on allergy symptoms have been reported recently [10-13]. The intake of Lactobacillus acidophilus L-92 reduced subjective symptoms in adult patients with atopic dermatitis [14]. L. casei strain Shirota suppressed systemic anaphylaxis in a mouse model of food allergy [15] and alleviated allergen-induced immune responses in allergic rhinitis in humans [16].

L. helveticus is a homo-fermentative, gram-positive, rod-shaped thermophilic LAB. These bacteria are used in the dairy industry as the starter for fermented milk and natural cheese manufacturing [17]. L. helveticus is a "Generally Recognized as Safe" microorganism, which was given the "Qualified Presumption of Safety" (QPS) status by the European Food Safety Authority (EFSA) [18]. The QPS status is the EFSA's safety evaluation label based on "the body of knowledge" or "familiarity" of a microorganism. Therefore, L. helveticus deserves QPS status, because it has a long history of apparent safe use in foods. L. helveticus is also sensitive to most 
antibiotics [19, 20]. Additionally, L. helveticus strains exhibit health promoting properties [21, 22].

L. helveticus SBT2171 (LH2171) originating from dairy products exhibits high proteolytic activity and is a common starter bacterial strain in the production of Gouda-type cheese [23]. In our previous study, LH2171 strongly inhibited the proliferation of primary murine immune cells and secretion of lipopolysaccharide-stimulated inflammatory cytokines (IL-6 and IL-1 $\beta$ ) by the immune cells in vitro [24]. Furthermore, in vivo administration of LH2171 suppressed the incidence and development of rheumatoid arthritis (an autoimmune disease) in a murine model $[25,26]$.

In this study, we investigated whether drinkable yoghurt (DY) containing LH2171 improved QOL in the subjects with daily nasal and ocular discomfort as the primary objective and determined life quality related scores according to the QOL questionnaire and diary as well as immune markers in the blood.

\section{METHODS}

\section{Preparation of study foods}

LH2171 was originally isolated by Milk Science Research Institute, Megmilk Snow Brand Co., Ltd. (Tokyo, Japan) and deposited in the International Patent Organism Depository at the National Institute of Advanced Industrial Science and Technology (Tsukuba, Ibaraki, Japan). Two types of DY were prepared: active DY that contained LH2171 and placebo DY that did not contain LH2171. The DY mixture consists of approximately $10 \%$ skimmed milk powder, $0.8 \%$ butter with a small amount of flavor, polysaccharide as a stabilizer, and sucralose as artificial sweetener. Active DY, containing LH2171, was fermented with starters composed of LH2171 and Streptococcus thermophilus. Placebo DY was fermented with Streptococcus thermophilus only. Both DYs were packaged, looked, and tasted the same. Total viable LAB counts were obtained by the plate counts method using BCP agar plates (Nissui, Tokyo, Japan). LH2171 total cell counts were determined by quantitative PCR. Briefly, it was performed with a ViiA ${ }^{\mathrm{TM}} 7$ Real-Time PCR System (Thermo Fisher Scientific, Tokyo, Japan) using L. helveticus specific primers and probe to target the phenylalanyl-tRNA synthetase $\alpha$-subunit (pheS), designed as hel_pheSF1 (5' -GAAGGCTTGGTAGTAGATAAGAACGTC-3' $)$, hel_pheSR4 (5 ' -AAGGCAAAACCACCGTAAACAG-3' ), and the locked nucleic acid probe h-P1 (5' -(6-FAM)_C+TACTCGT+CT+TCGTCCAAGT_(BHQ1)-3' ). Thunderbird probe qPCR mix (Toyobo, Tokyo, Japan) was used for PCR and the reaction was performed following the manufacturer's protocol. Briefly, each $10 \mu \mathrm{L}$ PCR reaction mixture consisted of THUNDERBIRD 
Probe qPCR Mix $5 \mu \mathrm{L}$ (TOYOBO, Tokyo, Japan), $0.3 \mu \mathrm{L}$ of each primer set $(10 \mu \mathrm{M}), 0.2 \mu \mathrm{L}$ of probe $(10 \mu \mathrm{M}), 50 \times$ ROX Reference $0.2 \mu \mathrm{L}, 0.5 \mu \mathrm{L}$ of template DNA, and $3.5 \mu \mathrm{L}$ sterile distilled water. The quantitative PCR reaction was performed with an initial denaturation of $95^{\circ} \mathrm{C}$ for 20 $\mathrm{sec}$, followed by $40 \mathrm{cycles}$ of $95^{\circ} \mathrm{C}$ for $1 \mathrm{sec}, 60^{\circ} \mathrm{C}$ for $60 \mathrm{~s}$. For the quantification of the number of LH2171 cells present in each sample, fluorescent signals detected in the linear range of the assay were averaged and compared to the standard curve generated with standard DNA in the same experiment. Each batch of DYs was consumed within 18 days after preparation. Study subjects were instructed to store DY in a refrigerator at below $10^{\circ} \mathrm{C}$ to maintain quality. Both DYs contained approximately $1.0 \times 10^{9}$ colony-forming units/g of LAB at the end of the consumption period. The active DY contained more than $1 \times 10^{7}$ cells/g of LH2171 at the end of the consumption period (Table 1).

Table 1. Nutrition of the study food.

\begin{tabular}{lccc}
\hline & Units & LH2171 & Placebo \\
\hline Energy & $\mathrm{kcal} / 100 \mathrm{~g}$ & 37 & 37 \\
Protein & $\mathrm{g} / 100 \mathrm{~g}$ & 3.0 & 3.0 \\
fat & $\mathrm{g} / 100 \mathrm{~g}$ & 0.6 & 0.6 \\
Carbohydrate & $\mathrm{g} / 100 \mathrm{~g}$ & 4.9 & 4.9 \\
Sodium & $\mathrm{mg} / 100 \mathrm{~g}$ & 39 & 39 \\
Lactobacillus helveticus SBT2171 & total cells counts/g & $\geqq 1 \times 10^{7}$ & N.D. \\
\hline
\end{tabular}

N.D.: Not detected.

\section{Study 1: effects of LH2171 on the nasal and ocular symptoms}

The randomized, double-blind, placebo-controlled, parallel group comparative study was conducted with two groups, the placebo group (P group) and LH2171 group (LH2171 group), throughout the month of June until December in 2017.

\section{Subjects}

From the individuals who agreed to participate in this study for payment, persons that met exclusion criteria (Table 2) were excluded. Then, long-term daily nasal and ocular discomforts were monitored before the start of the treatment period for one week. The participants were assessed by the physical examination. The levels of specific IgE antibodies against mites and house dust were measured in their samples. The inclusion criteria for this study were the following: (1) age of 20-64 years, (2) presence of nasal discomfort (sneezing, runny nose and/or nasal congestion), (3) positive for specific IgE against house dust or mites, (4) not having diseases other than allergy (Table 2). Based on these criteria, 100 subjects were enrolled in this 
study and randomized to two groups. The person in charge of randomization used random numbers to assign the study treatments to individual subjects. The allocation list was sealed in an envelope that was stored until the completion of data collection. The allocation was performed by Mr. Kibune (TTC Co. Ltd., Tokyo, Japan) and concealed from the subjects, physicians, and researchers who recruited and assessed the participating subjects.

Table 2. Exclusion criteria in study 1

1 Routine consumption of food and medicines containing lactic acid bacteria.

2 Routine consumption of food and medicines that may affect study results.

3 History of regular visits to otolaryngologist or a planned visit to a clinic.

4 Diagnosis of seasonal clinical rhinitis.

5 Diagnosis of acute rhinitis, sinusitis, or hypertrophic rhinitis.

6 Diagnosis of bronchial asthma.

7 Current medical treatment or history of a serious disease (e.g., diabetes, liver disease, kidney disease, or heart disease, respiratory disease, endocrine disease).

8 Current medication (e.g., hyposensitisation) that may affect study results.

9 Food allergy.

10 Unsuitability for the study as judged by the investigator on the basis of laboratory evidence or impaired cardiovascular function.

11 Disease requiring regular medication or history of serious diseases for which medication was required.

Unsuitability for the study as judged from the results of clinical and physical tests during the preliminary examination.

Participation in other clinical study within one month prior to the current study or

13 plan to participate in another clinical study after signing informed consent for the current study.

Pregnancy, lactation, or plan to become pregnant after signing informed consent for the current study.

15 Unsuitability for the study as judged from the data of the lifestyle questionnaire.

16 Unsuitability for the study as judged by the investigator for any other reason.

\section{Study design and schedule}

The primary outcome included the nasal and ocular symptom scores based on the QOL questionnaire and diaries, which were compared between groups. The secondary outcomes included life quality related scores based on the QOL questionnaire and diaries, referring to the 
Japanese guidelines for allergic rhinitis 2017 [3], as well as immune markers in the blood, which were compared between groups. To assess daily changes in symptoms, the subjects kept a symptom diary throughout the study periods. On weeks $0,4,8$, and 12 after the start of the treatment and 4 weeks after the end of treatment (week 16), the subjects attended the laboratory test site to be examined by a physician who evaluated their symptoms and QOL questionnaire based on the Japanese guidelines for allergic rhinitis 2017 [3] as well as to have blood and urine collected for analysis. During the study, the principal investigator and assistants instructed the subjects (1) not to change their lifestyle with respect to eating food, drinking alcohol, exercising, and sleeping, (2) to avoid over exercising and under- or overeating, (3) not to start exercising or change existing training habits, (4) to record a diary every day, (5) not to consume fermented milk and foods containing LAB except for the study diet, and if unavoidable to record such occurrences in the diary, (6) to avoid using anti-allergic drugs as much as possible, but when such drugs were used, to record the drug name and its usage frequency in the diary, (7) if medicines were used, to record their names and usage frequency in the diary, (8) to take a specified amount of the study food every day; and record the time and amount of the study food intake in the diary, and (9) to go to bed by 12 o'clock in the evening and get enough sleep before the examination visit. Furthermore, subjects were required (1) to limit intake of health food (food for specified health conditions, functional foods, health supplements, etc.) during the study period, (2) not to drink alcohol the day before the examination date, (3) to take a meal containing many fats at least $3 \mathrm{~h}$ before the visit on the day of examination (the subjects were fasted until the end of the examination), and (4) not to take the study food after the end of examination.

\section{Evaluation of symptoms and QOL by QOL questionnaire}

For the evaluation of the primary endpoint, the subjects responded to the questionnaire about the state of nasal or ocular discomfort in the last 1-2 weeks during the examination visit, referring to the Japanese guidelines for allergic rhinitis 2017 [3]. The questionnaire consisted of 22 items and was evaluated on a 5-point scale ranging from 0 (never uncomfortable) to 4 (very uncomfortable). In brief, the nasal or ocular symptom domains (rhinorrhoea, sneezing, nasal obstruction, nose itching, eye itching, and tearing), the life quality domain: daily living (reduced productivity at work/home, poor mental concentration, reduced thinking power, impaired book/newspaper reading, and memory loss), outdoor activities (limitation of outdoor life, e.g. sports, picnics, and decreased frequency of going out), social life (hesitation visiting friends or relatives, reduced contact with friends or others by telephone or conversation, and not an easy person to be around), 
impaired sleeping, and physical (tiredness and fatigue) and mental health (frustration, imitability, depression, and unhappiness), and general condition score (including the symptoms, life, and emotions) were evaluated. Total nasal and ocular symptoms, total nasal symptoms, and total ocular symptoms were obtained by adding symptom scores of the six items for the nasal and ocular symptoms domains, four items for the nasal domain (rhinorrhoea, sneezing, nasal obstruction, and nose itching), and two items for the ocular domain (eye itching and tearing), respectively.

\section{Evaluation of self-described nasal and ocular symptoms by diary}

We evaluated self-described conditions of the subjects' nasal and ocular symptoms based on the diaries they filled out, referring to the Japanese guidelines for allergic rhinitis 2017 [3]. The items in the diaries included the frequency of sneezes, nasal discharge (the number of nose blowing occurrences), nasal obstruction, nose itching, eye itching, tearing, and normal life activity. The conditions were scored on a 5-point scale, ranging from 0 (never uncomfortable) to 4 (very uncomfortable). When we evaluated the subjects' diaries, the number of sneezes, the number of nasal discharges, and each score recorded in the diaries were added up for one week before the start of the treatment period, every 4 weeks in the treatment periods, and 4 weeks after the end of the treatment period (baseline, weeks 1-4, weeks 5-8, weeks 9-12, and weeks 13-16, respectively).

\section{Study 2: safety of the excessive consumption of LH2171}

This study was designed as a single-arm, non-randomized, open-label study for 6 weeks and performed from August to December 2017 to evaluate the safety of the excessive consumption of the DY containing LH2171 in healthy adults.

\section{Subjects}

The subjects who did not meet any of the exclusion criteria (Table 3) were selected from the healthy adult males and females who responded to a recruiting advertisement about paid participation in this study. These subjects kept diaries about their nasal and ocular discomfort during the observation period before the start of the treatment period, had a physical examination, and got their specific blood IgE response to mites and house dust measured.

The inclusion criteria for the study were the following: (1) age of 20-64 years, (2) 10 individuals, half of all 20 subjects, with negative reaction for specific IgE antibodies against 
house dust and mites, (3) 10 individuals, the remaining half of the subjects, with nasal discomfort (sneezing, runny nose, nasal discharge) and positive test for specific IgE antibodies against house dust and mites. No subject deviated from the protocol during the study period. Accordingly, all 20 subjects were included in the analysis. The percentage of the study diet consumption was 99.5 $\pm 1.7 \%$.

Table 3. Exclusion criteria in study 2

1 Hospital visits for ocular or nasal discomfort or taking medicines that might affect the study results.

2 History of regular visits to otolaryngologist or a planned visit to a clinic.

3 Diagnosis of acute rhinitis, sinusitis, or hypertrophic rhinitis.

4 Diagnosis of bronchial asthma.

5 Allergy to test food in this study.

6 Unsuitability for the study as judged by the investigator on the basis of laboratory evidence or impaired cardiovascular function.

7 Current medical treatment or history of a serious disease for which a medication was required.

8 Unsuitability for the study as judged from the results of clinical and physical tests during the preliminary examination.

9 Participation in other clinical studies. 10 Pregnancy, lactation, or plan to become pregnant after signing informed consent for the current study.

11 Unsuitability for the study as judged from the data of the lifestyle questionnaire. 12 Unsuitability for the study as judged by the investigator for any other reason.

\section{Study design and schedule}

Subjects were instructed to consume the recommended daily intake of DY containing LH2171 three times a day for 4 weeks. Urine and blood samples were collected during the observation period before the start of the treatment (baseline), at weeks 2 and 4 after the start of the treatment, and two weeks after the end of the treatment (week 6). During the study, the principal investigator and assistants instructed the subjects about the same prohibited matters.

\section{Anthropometric measurements}


Body height, body weight, systolic blood pressure (SBP), diastolic blood pressure (DBP), pulse rate, and body temperature were measured at the scheduled time points. Body mass index (BMI) was calculated based on the body height and body weight.

\section{Blood analysis}

The following haematological parameters were measured in the subjects' blood samples at the scheduled time points: white and red blood cell counts, haemoglobin, haematocrit, and blood platelets. Biochemical parameters included total protein (TP), albumin (ALB), aspartate aminotransferase (AST), alanine transaminase (ALT), lactate dehydrogenase (LD), alkaline phosphatase (ALP), gamma-glutamyl-transpeptidase ( $\gamma \mathrm{GTP}$ ), total bilirubin (TB), direct bilirubin (DB), internal bilirubin (IB), creatinine (Cre), blood urea nitrogen (UN), uric acid (UA), total cholesterol (TC), high-density lipoprotein cholesterol (HDL-C), low-density lipoprotein cholesterol (LDL-C), triglycerides (TG), sodium (Na), chloride $(\mathrm{K})$, potassium $(\mathrm{Cl})$, and glucose (GLU). IgE antibodies (total, specific for house dust 1, and specific for mites (Dermatophagoides pteronyssinus)) were determined by LSI Medience Inc. (Tokyo, Japan), and interferon- $\gamma$ (IFN $\gamma$ ) and IL-13 were determined by SRL (Osaka, Japan).

\section{Urinalysis}

Urinalysis parameters including glucose (qualitative), protein (qualitative), and occult blood were measured at the scheduled time points by LSI Medience Inc.

\section{Adverse events}

Physicians examined the results of the medical review and self-record diary at the scheduled time points; the relationship between those results and the intake of study food was determined.

\section{Ethics}

Each study was conducted in accordance with the Declaration of Helsinki. For study 1, all procedures involving human subjects were approved by the Aisei Hospital Ueno Clinic Research Ethics Committee, Tokyo, Japan on June $8^{\text {th }}, 2017$ (Institutional Review Board Reporting System of the Ministry of Health, Labour and Welfare; IRB number: 12000071). For study 2, procedures were approved by the Human Trials Committee of the Kenshokai Ethical Review Board, Osaka, Japan, on August $8^{\text {th }}$, 2017 (Institutional Review Board Reporting System of the Ministry of Health, Labour and Welfare; IRB number: 14000047). Information about these studies, including 
the study outline, methods, expected effects and side effects, and protection of privacy, was given to all subjects. Written informed consent was obtained from all subjects prior to enrollment.

\section{Statistics}

Data are shown as the mean \pm standard deviation. IgE antibody titres were common log-transformed in study 1. Anthropometric measurements and serum biomarkers were analyzed by the Student's paired $t$-test to examine the difference between the initial values (week 0 in study 1 or baseline in study 2) and the values at each analysis point during the treatment period. The differences between the initial values of urinary biomarkers and their values at each analysis point were analyzed by the Wilcoxon signed-rank test. The QOL questionnaire scores from the diaries were evaluated by the Wilcoxon signed-rank test to examine the significance of the differences between the initial values and the values at each analysis point during the treatment, and by the Mann-Whitney $U$ test to compare the values in P group and LH2171 group. The values of the difference between the initial QOL questionnaire scores and scores at each recorded point in the diaries were analyzed by the Mann-Whitney $U$ test between the groups. All data were analyzed using IBM SPSS Statistics software, version 23 (IBM Japan, Tokyo, Japan). All statistical analyses were conducted with a significance level of $\alpha=0.05(P<0.05)$.

\section{RESULTS}

\section{Study 1}

\section{Subjects}

The study outline is shown in Figure 1. We initially selected 45 males and 55 females as the subjects of the study. Three subjects in the placebo group withdrew their consent to participate in the study and dropped out, so 97 subjects completed the predetermined schedule and examinations. The intake rate of the study food by the subjects who completed the study was 94.4\%. Three more subjects were excluded from the efficacy analysis as they met some exclusion criteria described in Table 4. Thus, the efficacy analysis was conducted in 94 subjects who completed the predetermined schedule and examinations (LH2171 group, $n=48$; P group, $n$ $=46)$.

For one subject, it was difficult to visit the clinic on week 12 for the efficacy analysis due to a left-hand fracture. Therefore, on week 12, he skipped the general clinical examination and specific IgE test. In 4 weeks after the end of the treatment period, all examinations were 
conducted, because his injury healed. Safety analyses for adverse events were performed in the 100 subjects who had taken the test sample at least once.

The background characteristics for each group are shown in Table 5. There were no significant differences between the groups in gender, age, height, weight, BMI, systolic blood pressure, diastolic blood pressure, pulse rate, QOL symptom score, total IgE level, or antigen-specific IgE levels.

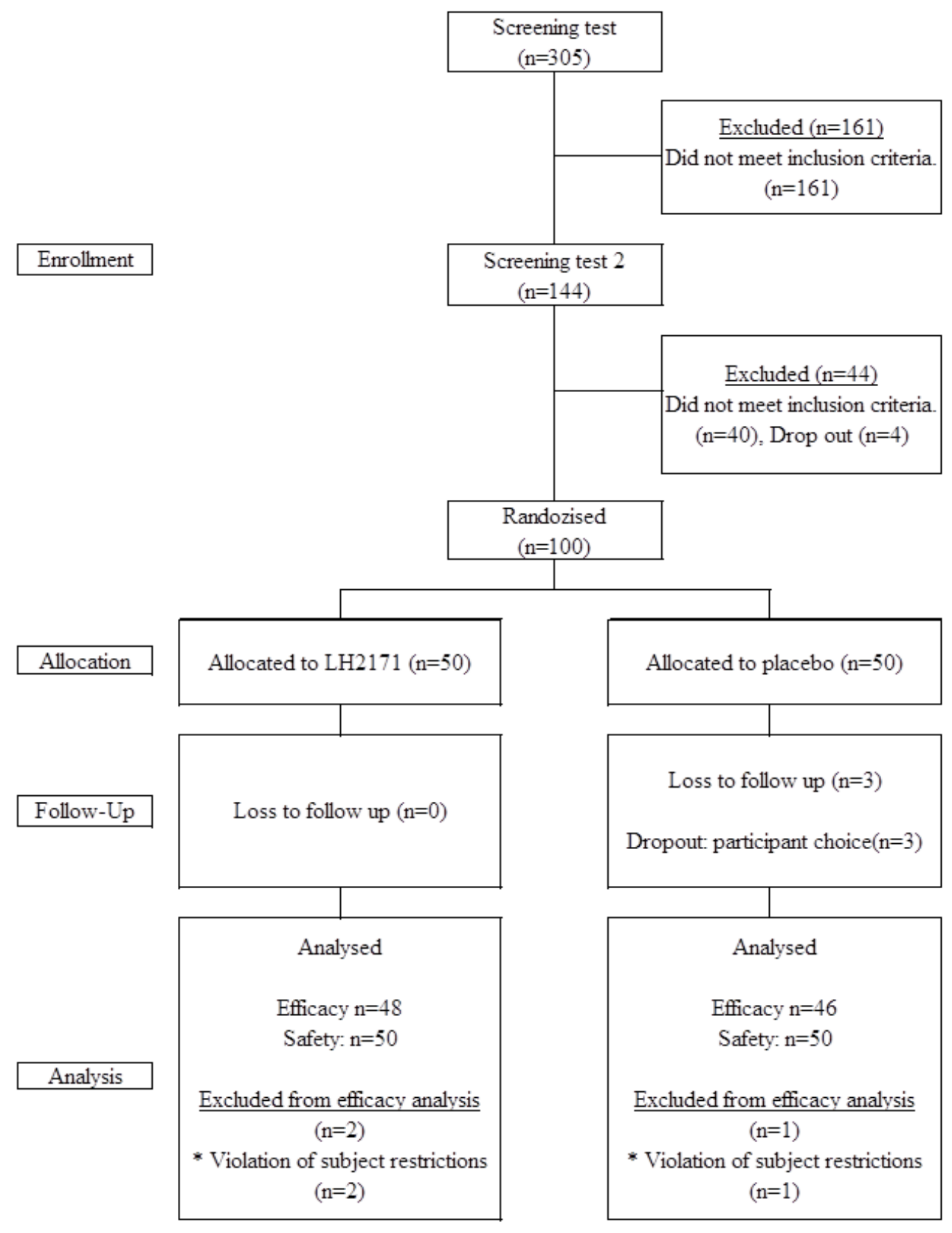

Figure 1. Flow diagram for study 1. 
Table 4. Criteria for exclusion from the efficacy analysis in study 1

1 Intake rate of test food below $80 \%$.

2

Suspected problems with credibility of the inspection results, e.g. due to the loss of diary records.

3

Non-compliance with the exclusion criteria revealed after the study or difficulty to comply with the restriction conditions during the study period.

Table 5: Characteristics of the subjects at allocation in study 1.

\begin{tabular}{|c|c|c|c|c|c|}
\hline & Items & Unit & LH2171 group & placebo group & $P$ value \\
\hline \multicolumn{2}{|c|}{ Number of subjects } & & 50 & 50 & \multirow{3}{*}{0.84} \\
\hline \multirow{2}{*}{ Gender } & Male & $\mathrm{n}$ & 23 & 21 & \\
\hline & Female & & 25 & 25 & \\
\hline \multicolumn{2}{|l|}{ Age } & & $39.6 \pm 12.2$ & $39.7 \pm 10.6$ & 0.98 \\
\hline \multicolumn{2}{|l|}{ Height } & $\mathrm{cm}$ & $164.50 \pm 8.72$ & $165.89 \pm 8.56$ & 0.44 \\
\hline \multicolumn{2}{|l|}{ Weight } & $\mathrm{kg}$ & $59.50 \pm 9.98$ & $60.02 \pm 9.25$ & 0.79 \\
\hline \multicolumn{2}{|l|}{ BMI } & $\mathrm{kg} / \mathrm{m}^{2}$ & $21.89 \pm 2.48$ & $21.78 \pm 2.67$ & 0.83 \\
\hline \multicolumn{2}{|c|}{ Systolic blood pressure } & $\mathrm{mmHg}$ & $110.2 \pm 14.4$ & $111.0 \pm 12.5$ & 0.80 \\
\hline \multicolumn{2}{|c|}{ Diastolic blood pressure } & $\mathrm{mmHg}$ & $66.4 \pm 9.5$ & $67.2 \pm 9.4$ & 0.68 \\
\hline \multicolumn{2}{|c|}{ Pulse rate } & beat/min & $73.3 \pm 9.9$ & $72.6 \pm 9.2$ & 0.71 \\
\hline \multicolumn{6}{|c|}{ QOL symptom score } \\
\hline \multicolumn{3}{|c|}{$\begin{array}{l}\text { Total score of nasal and } \\
\text { ocular symptoms }\end{array}$} & $6.6 \pm 3.7$ & $5.9 \pm 3.2$ & 0.53 \\
\hline \multicolumn{3}{|c|}{$\begin{array}{l}\text { Total score of nasal } \\
\text { symptoms }\end{array}$} & $4.6 \pm 2.7$ & $4.0 \pm 2.2$ & 0.41 \\
\hline \multicolumn{3}{|c|}{$\begin{array}{l}\text { Total score of eye } \\
\text { symptoms }\end{array}$} & $1.9 \pm 1.7$ & $1.9 \pm 1.5$ & 0.92 \\
\hline \multicolumn{3}{|c|}{ rhinorrhea } & $1.1 \pm 1.0$ & $1.1 \pm 0.9$ & 0.99 \\
\hline \multicolumn{3}{|c|}{ sneezing } & $1.3 \pm 0.7$ & $1.2 \pm 0.8$ & 0.42 \\
\hline \multicolumn{3}{|c|}{ nasal obsrtraction } & $1.0 \pm 1.0$ & $0.8 \pm 0.8$ & 0.72 \\
\hline \multicolumn{3}{|c|}{ nose itching } & $1.2 \pm 0.9$ & $0.9 \pm 0.8$ & 0.08 \\
\hline \multicolumn{3}{|c|}{ eye itching } & $1.2 \pm 1.0$ & $1.1 \pm 0.9$ & 0.78 \\
\hline & tearing & & $0.7 \pm 0.9$ & $0.8 \pm 0.8$ & 0.66 \\
\hline \multicolumn{6}{|l|}{ specific IgE } \\
\hline \multirow{3}{*}{\multicolumn{2}{|c|}{$\begin{array}{l}\text { Mite } \\
\text { House dust } 1\end{array}$}} & $\log (\mathrm{IU} / \mathrm{mL})$ & $0.903 \pm 0.558$ & $0.808 \pm 0.568$ & 0.42 \\
\hline & & $\log (\mathrm{IU} / \mathrm{mL})$ & $0.809 \pm 0.559$ & $0.724 \pm 0.544$ & 0.46 \\
\hline & & $\log (\mathrm{IU} / \mathrm{mL})$ & $2.2 \pm 0.5$ & $2.1 \pm 0.6$ & 0.20 \\
\hline
\end{tabular}

4 Presence of obvious reasons that necessitated the exclusion from the study.

Values are expressed as the mean \pm standard deviation. Analyses were performed using the chi-squared test for gender, Mann-Whitney's $U$ test for the QOL symptoms score, and Student's $t$-test for other items. 


\section{Nasal and ocular symptoms according to the QOL questionnaire}

Decreases in the total scores of the nasal and ocular discomforts between week 0 and week 8 in LH2171 group were significantly larger than those in P group. On week 12, the decrease in the score in LH2171 group was still larger than in P group, similar to the observation on week 8. However, the alleviating effect did not reach statistical significance $(P=0.173$; Table 6I). Analysis of values within the group showed that the total scores of the nasal and ocular symptoms were significantly lower on weeks 8, 12, and 16 than on week 0 in LH2171 group (Table 6II). In contrast, in P group the score significantly decreased only on week 16 compared to the value on week 0 (Table 6II).

Table 6. Score on the QOL questionnaire in study 1.

I. Score of change from week 0 in nasal and ocular symptoms.

\begin{tabular}{|c|c|c|c|c|c|c|}
\hline Items & Group & $\mathrm{n}$ & $\Delta$ week 4 & $\Delta$ week 8 & $\Delta$ week 12 & $\Delta$ week 16 \\
\hline $\begin{array}{l}\text { Nasal and Ocular } \\
\text { symptoms (total }\end{array}$ & LH2171 & 48 & $-0.8 \pm 2.9$ & $-1.6 \pm 3.5^{\#}$ & $-1.6 \pm 3.6$ & $-2.7 \pm 3.6$ \\
\hline score) & Placebo & 46 & $-0.3 \pm 2.8$ & $-0.2 \pm 3.1$ & $-0.7 \pm 3.2$ & $-2.0 \pm 3.1$ \\
\hline \multirow{2}{*}{$\begin{array}{l}\text { Nasal symptoms } \\
\text { (total score) }\end{array}$} & LH2171 & 48 & $-0.4 \pm 2.3$ & $-1.0 \pm 2.7^{\#}$ & $-1.0 \pm 2.8$ & $-1.7 \pm 2.8$ \\
\hline & Placebo & 46 & $0.0 \pm 2.6$ & $0.0 \pm 2.4$ & $-0.2 \pm 2.5$ & $-1.1 \pm 2.4$ \\
\hline \multirow{2}{*}{$\begin{array}{l}\text { Ocular symptoms } \\
\text { (total score) }\end{array}$} & LH2171 & 48 & $-0.3 \pm 1.2$ & $-0.7 \pm 1.4$ & $-0.6 \pm 1.6$ & $-1.0 \pm 1.6$ \\
\hline & Placebo & 46 & $-0.4 \pm 1.0$ & $-0.2 \pm 1.1$ & $-0.5 \pm 1.2$ & $-0.9 \pm 1.2$ \\
\hline \multirow{2}{*}{ Rhinorrhea } & LH2171 & 48 & $-0.1 \pm 0.8$ & $-0.1 \pm 1.0$ & $-0.1 \pm 1.0$ & $-0.3 \pm 1.0$ \\
\hline & Placebo & 46 & $0.1 \pm 1.0$ & $-0.1 \pm 0.9$ & $0.1 \pm 1.1$ & $-0.3 \pm 1.0$ \\
\hline \multirow{2}{*}{ Sneezing } & LH2171 & 48 & $0.0 \pm 0.7$ & $-0.2 \pm 0.8$ & $-0.3 \pm 0.9$ & $-0.5 \pm 0.9$ \\
\hline & Placebo & 46 & $-0.1 \pm 0.9$ & $0.0 \pm 0.9$ & $-0.2 \pm 0.8$ & $-0.3 \pm 0.8$ \\
\hline \multirow{2}{*}{ Nasal obstruction } & LH2171 & 48 & $-0.1 \pm 0.8$ & $-0.2 \pm 1.0$ & $-0.2 \pm 1.0$ & $-0.2 \pm 1.0$ \\
\hline & Placebo & 46 & $0.1 \pm 0.9$ & $0.2 \pm 0.7$ & $0.1 \pm 0.9$ & $0.0 \pm 0.9$ \\
\hline \multirow{2}{*}{ Nose itching } & LH2171 & 48 & $-0.2 \pm 0.8$ & $-0.5 \pm 0.9^{\# \#}$ & $-0.5 \pm 0.8$ & $-0.7 \pm 0.8$ \\
\hline & Placebo & 46 & $-0.1 \pm 0.7$ & $0.0 \pm 0.7$ & $-0.2 \pm 1.0$ & $-0.4 \pm 0.9$ \\
\hline \multirow{2}{*}{ Eye itching } & LH2171 & 48 & $-0.1 \pm 0.7$ & $-0.4 \pm 0.8$ & $-0.4 \pm 0.9$ & $-0.6 \pm 0.9$ \\
\hline & Placebo & 46 & $-0.3 \pm 0.6$ & $-0.1 \pm 0.8$ & $-0.3 \pm 0.8$ & $-0.5 \pm 0.8$ \\
\hline \multirow{2}{*}{ Tearing } & LH2171 & 48 & $-0.2 \pm 0.6$ & $-0.3 \pm 0.7$ & $-0.2 \pm 0.9$ & $-0.4 \pm 0.9$ \\
\hline & Placebo & 46 & $-0.1 \pm 0.6$ & $-0.1 \pm 0.5$ & $-0.2 \pm 0.6$ & $-0.4 \pm 0.7$ \\
\hline
\end{tabular}

II. Nasal and ocular symptoms score.

\begin{tabular}{|c|c|c|c|c|c|c|c|}
\hline Items & Group & $\mathrm{n}$ & week 0 & week 4 & week 8 & week 12 & week 16 \\
\hline $\begin{array}{l}\text { Nasal and Ocular } \\
\text { symptoms(total }\end{array}$ & LH2171 & 48 & $6.6 \pm 3.7$ & $5.8 \pm 3.4$ & $4.9 \pm 3.2 * *$ & $4.9 \pm 3.1 * *$ & $3.8 \pm 2.5 * * *$ \\
\hline score) & Placebo & 46 & $5.9 \pm 3.2$ & $5.6 \pm 3.8$ & $5.7 \pm 3.1$ & $5.2 \pm 3.0$ & $4.0 \pm 2.6^{* * *}$ \\
\hline Nasal symptoms & LH2171 & 48 & $4.6 \pm 2.7$ & $4.2 \pm 2.7$ & $3.7 \pm 2.4^{*}$ & $3.6 \pm 2.3^{*}$ & $2.9 \pm 2.1 * * *$ \\
\hline (total score) & Placebo & 46 & $4.0 \pm 2.2$ & $4.1 \pm 3.0$ & $4.0 \pm 2.3$ & $3.8 \pm 2.3$ & $3.0 \pm 2.0 * *$ \\
\hline Ocular & LH2171 & 48 & $1.9 \pm 1.7$ & $1.6 \pm 1.3$ & $1.3 \pm 1.2 * *$ & $1.3 \pm 1.2^{*}$ & $0.9 \pm 0.9 * * *$ \\
\hline symptoms & Placebo & 46 & $1.9 \pm 1.5$ & $1.5 \pm 1.4^{*}$ & $1.7 \pm 1.4$ & $1.4 \pm 1.3 * *$ & $1.0 \pm 1.0 * * *$ \\
\hline
\end{tabular}


(total score)

$\begin{array}{llllllll}\text { Rhinorrhea } & \text { LH2171 } & 48 & 1.1 \pm 1.0 & 1.0 \pm 1.0 & 1.0 \pm 0.7 & 1.0 \pm 0.7 & 0.8 \pm 0.7^{*} \\ & \text { Placebo } & 46 & 1.1 \pm 0.9 & 1.2 \pm 1.0 & 1.0 \pm 0.8 & 1.2 \pm 0.9 & 0.8 \pm 0.7 \\ \text { Sneezing } & \text { LH2171 } & 48 & 1.3 \pm 0.7 & 1.3 \pm 0.8 & 1.1 \pm 0.6 & 1.0 \pm 0.7 & 0.8 \pm 0.7^{* * *} \\ \text { Nasal } & \text { Placebo } & 46 & 1.2 \pm 0.8 & 1.1 \pm 0.9 & 1.2 \pm 0.7 & 1.0 \pm 0.7 & 0.8 \pm 0.6^{* *} \\ \text { obstruction } & \text { LH2171 } & 48 & 1.0 \pm 1.0 & 0.9 \pm 0.8 & 0.8 \pm 0.9 & 0.8 \pm 1.0 & 0.8 \pm 0.8 \\ \text { Nose itching } & \text { Placebo } & 46 & 0.8 \pm 0.8 & 0.9 \pm 0.9 & 1.0 \pm 0.7 & 0.9 \pm 0.7 & 0.8 \pm 0.7 \\ & \text { LH2171 } & 48 & 1.2 \pm 0.9 & 1.0 \pm 0.8 & 0.8 \pm 0.8^{* *} & 0.8 \pm 0.7^{* *} & 0.6 \pm 0.6^{* * *} \\ \text { Eye itching } & \text { Placebo } & 46 & 0.9 \pm 0.8 & 0.9 \pm 0.8 & 0.9 \pm 0.6 & 0.7 \pm 0.7 & 0.5 \pm 0.5^{* *} \\ & \text { LH2171 } & 48 & 1.2 \pm 1.0 & 1.1 \pm 0.8 & 0.8 \pm 0.7 * * & 0.8 \pm 0.8^{* *} & 0.6 \pm 0.6^{* * *} \\ \text { Tearing } & \text { Placebo } & 46 & 1.1 \pm 0.9 & 0.9 \pm 0.9 * & 1.0 \pm 0.9 & 0.8 \pm 0.8^{*} & 0.7 \pm 0.7^{* * *} \\ & \text { LH2171 } & 48 & 0.7 \pm 0.9 & 0.5 \pm 0.7 & 0.5 \pm 0.6^{*} & 0.5 \pm 0.6 & 0.3 \pm 0.5^{* *} \\ & \text { Placebo } & 46 & 0.8 \pm 0.8 & 0.7 \pm 0.7 & 0.7 \pm 0.6 & 0.6 \pm 0.8 & 0.3 \pm 0.5^{* * *}\end{array}$

III. Score of change from week 0 related life quality.

\begin{tabular}{|c|c|c|c|c|c|c|c|}
\hline Items & Group & $\mathrm{n}$ & $\Delta$ week 4 & $\Delta$ week 8 & $\Delta$ week 12 & $\Delta$ week 16 & \\
\hline \multirow{2}{*}{ Daily living } & LH2171 & 48 & $-0.1 \pm 3.5$ & $-0.6 \pm 3.2$ & $-1.1 \pm 3.1$ & $-1.3 \pm 3.3$ & \\
\hline & Placebo & 46 & $-0.3 \pm 3.0$ & $-0.4 \pm 2.9$ & $-0.7 \pm 2.8$ & $-1.4 \pm 2.9$ & \\
\hline \multirow{2}{*}{$\begin{array}{l}\text { Outdoor } \\
\text { activities }\end{array}$} & LH2171 & 48 & $0.3 \pm 1.3$ & $-0.1 \pm 1.2$ & $-0.3 \pm 1.0^{\#}$ & $-0.2 \pm 1.1$ & \\
\hline & Placebo & 46 & $0.2 \pm 1.2$ & $0.2 \pm 1.4$ & $0.0 \pm 0.9$ & $-0.2 \pm 1.2$ & \\
\hline \multirow{2}{*}{ Social life } & LH2171 & 48 & $-0.1 \pm 2.2$ & $-0.5 \pm 1.6$ & $-0.6 \pm 1.5$ & $-0.5 \pm 1.7$ & \\
\hline & Placebo & 46 & $-0.2 \pm 1.5$ & $-0.1 \pm 1.8$ & $-0.5 \pm 1.8$ & $-0.6 \pm 2.2$ & \\
\hline \multirow{2}{*}{ Sleep } & LH2171 & 48 & $-0.1 \pm 0.8$ & $-0.3 \pm 0.7^{\#}$ & $-0.3 \pm 0.7^{\#}$ & $-0.4 \pm 0.8$ & \\
\hline & Placebo & 46 & $0.2 \pm 0.7$ & $0.1 \pm 0.6$ & $0.0 \pm 0.9$ & $0.0 \pm 0.7$ & \\
\hline \multirow{2}{*}{ Physical } & LH2171 & 48 & $-0.3 \pm 1.5$ & $-0.3 \pm 1.0$ & $-0.6 \pm 1.3$ & $-0.8 \pm 1.4$ & \\
\hline & Placebo & 46 & $-0.2 \pm 1.3$ & $-0.3 \pm 2.0$ & $-0.4 \pm 1.7$ & $-0.7 \pm 1.5$ & \\
\hline \multirow{2}{*}{ Mental health } & LH2171 & 48 & $-0.3 \pm 3.2$ & $-0.8 \pm 2.4$ & $-1.0 \pm 2.3$ & $-1.4 \pm 2.7$ & \\
\hline & Placebo & 46 & $0.1 \pm 1.9$ & $0.0 \pm 3.2$ & $-0.5 \pm 2.9$ & $-0.7 \pm 2.9$ & \\
\hline \multicolumn{8}{|c|}{ Life quality related score. } \\
\hline Items & Group & $\mathrm{n}$ & week 0 & week 4 & week 8 & week 12 & week 16 \\
\hline \multirow{2}{*}{ Daily living } & LH2171 & 48 & $3.7 \pm 3.1$ & $3.6 \pm 3.9$ & $3.1 \pm 2.9$ & $2.5 \pm 2.5^{* *}$ & $2.4 \pm 2.6^{* * *}$ \\
\hline & Placebo & 46 & $3.2 \pm 2.7$ & $3.0 \pm 3.1$ & $2.8 \pm 2.9$ & $2.5 \pm 2.7$ & $1.8 \pm 2.4^{* *}$ \\
\hline \multirow{2}{*}{$\begin{array}{l}\text { Outdoor } \\
\text { activities }\end{array}$} & LH2171 & 48 & $0.6 \pm 1.1$ & $0.9 \pm 1.6$ & $0.6 \pm 1.0$ & $0.3 \pm 0.8^{*}$ & $0.4 \pm 0.8$ \\
\hline & Placebo & 46 & $0.6 \pm 1.0$ & $0.8 \pm 1.1$ & $0.8 \pm 1.4$ & $0.5 \pm 0.9$ & $0.4 \pm 0.8$ \\
\hline \multirow{2}{*}{ Social life } & LH2171 & 48 & $1.4 \pm 1.9$ & $1.3 \pm 2.2$ & $0.9 \pm 1.4^{*}$ & $0.8 \pm 1.3^{* *}$ & $0.9 \pm 1.5$ \\
\hline & Placebo & 46 & $1.3 \pm 2.1$ & $1.2 \pm 1.7$ & $1.3 \pm 1.9$ & $0.8 \pm 1.5$ & $0.7 \pm 1.4$ \\
\hline \multirow{2}{*}{ Sleep } & LH2171 & 48 & $0.7 \pm 0.9$ & $0.6 \pm 0.9$ & $0.4 \pm 0.8^{* *}$ & $0.4 \pm 0.7^{* *}$ & $0.4 \pm 0.6^{* *}$ \\
\hline & Placebo & 46 & $0.4 \pm 0.7$ & $0.6 \pm 0.8$ & $0.5 \pm 0.7$ & $0.4 \pm 0.7$ & $0.4 \pm 0.6$ \\
\hline \multirow{2}{*}{ Physical } & LH2171 & 48 & $1.7 \pm 1.7$ & $1.4 \pm 1.8$ & $1.4 \pm 1.6^{*}$ & $1.1 \pm 1.4^{* *}$ & $0.9 \pm 1.2^{* * *}$ \\
\hline & Placebo & 46 & $1.5 \pm 1.4$ & $1.3 \pm 1.7$ & $1.2 \pm 1.7$ & $1.1 \pm 1.3$ & $0.8 \pm 1.1^{* *}$ \\
\hline \multirow{2}{*}{ Mental health } & LH2171 & 48 & $2.6 \pm 3.1$ & $2.3 \pm 3.3$ & $1.8 \pm 2.2^{*}$ & $1.6 \pm 2.1^{* *}$ & $1.2 \pm 1.7^{* * * *}$ \\
\hline & Placebo & 46 & $1.9 \pm 2.6$ & $2.0 \pm 2.5$ & $1.9 \pm 2.9$ & $1.3 \pm 2.2$ & $1.2 \pm 2.0$ \\
\hline
\end{tabular}

V. Score of change from week 0 on general condition. 


\begin{tabular}{|c|c|c|c|c|c|c|c|}
\hline Items & Group & $\mathrm{n}$ & $\Delta$ week 4 & $\Delta$ week 8 & $\Delta$ week 12 & $\Delta$ week 16 & \\
\hline \multirow{2}{*}{$\begin{array}{l}\text { General } \\
\text { condition }\end{array}$} & LH2171 & 48 & $-0.2 \pm 0.7$ & $-0.3 \pm 0.9$ & $-0.4 \pm 0.8$ & $-0.3 \pm 0.8$ & \\
\hline & Placebo & 46 & $-0.2 \pm 0.8$ & $-0.2 \pm 1.0$ & $-0.3 \pm 1.1$ & $-0.5 \pm 1.0$ & \\
\hline \multicolumn{8}{|c|}{ I. General condition score. } \\
\hline Items & Group & $\mathrm{n}$ & week 0 & week 4 & week 8 & week 12 & week 16 \\
\hline \multirow{2}{*}{$\begin{array}{l}\text { General } \\
\text { condition }\end{array}$} & LH2171 & 48 & $1.8 \pm 0.8$ & $1.5 \pm 0.7$ & $1.5 \pm 0.8^{*}$ & $1.4 \pm 0.7^{* *}$ & $1.4 \pm 0.8^{* *}$ \\
\hline & Placebo & 46 & $1.8 \pm 0.9$ & $1.6 \pm 0.9$ & $1.7 \pm 0.9$ & $1.5 \pm 0.8$ & $1.3 \pm 0.8^{* *}$ \\
\hline
\end{tabular}

Data are expressed as the mean \pm standard deviation. ${ }^{\#} P<0.05,{ }^{\# \#} P<0.01$ between the groups by Man-Whitney $U$ test. $* P<0.05$, $* * P<0.01, * * * P<0.001$ compared to the week 0 by the Wilcoxon signed rank test.

\section{Nasal discomfort total score according to the QOL questionnaire}

The decreases of the nasal discomfort total score between week 0 and week 8 were significantly larger in LH2171 group than in P group (Table 6I), while there was no significant difference between the groups on week $12(P=0.149$; Table 6I). Within-group comparisons demonstrated that the nasal discomfort total score significantly decreased on weeks 8,12 , and 16 compared to that on week 0 in LH2171 group (Table 6II).

\section{Ocular discomfort total score according to the QOL questionnaire}

There were no significant differences between the groups in the changes of the total ocular discomfort score compared to the value on week 0 at any experimental point (Table 6I). Within-group comparisons showed that the ocular discomfort total score significantly decreased on weeks 8, 12, and 16 compared to the value on week 0 in LH2171 group, and on weeks 4, 12, and 16 in $\mathrm{P}$ group (Table 6II).

\section{Life quality related scores according to the QOL questionnaire}

Changes in outdoor activity scores from week 0 to week 12 demonstrated a significant improvement in LH2171 group compared to P group (Table 6III). Furthermore, changes in the sleep score compared to the value on week 0 also indicated significantly higher improvement in LH2171 group on week 8 and on week 12 (Table 6III). Within-group comparisons demonstrated that daily living, outdoor activity, social life, sleep, physical, and mental health scores were significantly improved in LH2171 group compared to the values on week 0 (Table IV). In the P group, daily living and physical scores were significantly improved only on week 16 compared with week 0 (Table IV).

\section{General condition score according to the QOL questionnaire}

No significant differences were observed between the two groups with changes of the general condition score compared to the value on week 0 at different points (Table 6V). Within-group comparisons demonstrated that general condition scores were significantly lower on weeks 8,12 , and 16 in LH2171 group and on week 16 in P group than on week 0 (Table VI).

\section{Nasal and ocular discomfort according to the diary}

The difference in the number of sneezes from baseline was significantly lower in LH2171 group than in $\mathrm{P}$ group on weeks 9-12 (Table 7I). Within-group comparison demonstrated that the 
number of sneezes in the LH2171 group was significantly decreased on weeks 9-12 and on weeks 13-16 compared with those at the baseline (Table 7II).

There were no significant differences between the groups in the degree of changes from baseline at any treatment period for the number of nose blowing and the score for nasal discharge, nasal obstruction, nose itching, eye itching, tearing, and normal life activity (Table 7I). Within-group comparisons showed that the scores for nasal obstruction, nose itching, eye itching, tearing, and normal life activity significantly improved on weeks 9-12 and on weeks 13-16 compared to the respective baseline values in LH2171 group (Table 7II). In P group, the scores for nose itching, eye itching, and tearing were significantly improved on weeks 5-8, 9-12, and 13-16 compared with the respective baseline values (Table 7II).

Table 7: Symptoms recorded diary in study 1.

I. Score of change from base line.

\begin{tabular}{lcccccc}
\hline Item & Group & $\mathrm{n}$ & week 1 to 4 & week 5 to 8 & week 9 to12 & week 13 to 16 \\
\hline $\begin{array}{l}\text { The number of } \\
\text { sneezes }\end{array}$ & LH2171 & 48 & $-0.05 \pm 0.42$ & $-0.01 \pm 0.43$ & $-0.10 \pm 0.51^{\#}$ & $-0.21 \pm 0.47$ \\
& Placebo & 46 & $-0.03 \pm 0.39$ & $-0.02 \pm 0.53$ & $0.04 \pm 0.52$ & $-0.10 \pm 0.46$ \\
$\begin{array}{l}\text { The number of } \\
\text { blown nose }\end{array}$ & LH2171 & 48 & $-0.08 \pm 0.38$ & $-0.08 \pm 0.42$ & $-0.04 \pm 0.47$ & $-0.08 \pm 0.48$ \\
Placebo & 46 & $-0.08 \pm 0.48$ & $-0.03 \pm 0.64$ & $0.10 \pm 0.69$ & $0.09 \pm 0.71$ \\
Nasal & LH2171 & 48 & $-0.10 \pm 0.48$ & $-0.09 \pm 0.55$ & $-0.17 \pm 0.53$ & $-0.24 \pm 0.60$ \\
obstruction & Placebo & 46 & $-0.03 \pm 0.72$ & $-0.02 \pm 0.74$ & $-0.03 \pm 0.90$ & $-0.10 \pm 0.88$ \\
& LH2171 & 48 & $-0.37 \pm 0.68$ & $-0.47 \pm 0.74$ & $-0.60 \pm 0.82$ & $-0.70 \pm 0.74$ \\
Nose itching & Placebo & 46 & $-0.15 \pm 0.65$ & $-0.30 \pm 0.76$ & $-0.34 \pm 0.86$ & $-0.49 \pm 0.81$ \\
& LH2171 & 48 & $-0.30 \pm 0.56$ & $-0.45 \pm 0.64$ & $-0.49 \pm 0.71$ & $-0.67 \pm 0.69$ \\
Eye itching & Placebo & 46 & $-0.27 \pm 0.65$ & $-0.39 \pm 0.76$ & $-0.36 \pm 0.75$ & $-0.51 \pm 0.69$ \\
& LH2171 & 48 & $-0.19 \pm 0.64$ & $-0.27 \pm 0.74$ & $-0.33 \pm 0.83$ & $-0.43 \pm 0.81$ \\
Tearing & Placebo & 46 & $-0.12 \pm 0.57$ & $-0.21 \pm 0.56$ & $-0.23 \pm 0.64$ & $-0.25 \pm 0.54$ \\
Normal & LH2171 & 48 & $-0.06 \pm 0.54$ & $-0.12 \pm 0.51$ & $-0.24 \pm 0.53$ & $-0.31 \pm 0.55$ \\
activity & Placebo & 46 & $-0.03 \pm 0.71$ & $-0.08 \pm 0.82$ & $-0.10 \pm 0.92$ & $-0.14 \pm 0.88$ \\
\hline
\end{tabular}

II. Symptoms score.

\begin{tabular}{lccccccc}
\hline Item & Group & $\mathrm{n}$ & baseline & week 1 to 4 & week 5 to 8 & week 9 to12 & week 13 to 16 \\
\hline $\begin{array}{l}\text { The number of } \\
\text { sneezes }\end{array}$ & LH2171 & 48 & $0.99 \pm 0.60$ & $0.94 \pm 0.62$ & $0.98 \pm 0.62$ & $0.89 \pm 0.60^{*}$ & $0.77 \pm 0.58^{* *}$ \\
& Placebo & 46 & $0.98 \pm 0.44$ & $0.95 \pm 0.48$ & $0.95 \pm 0.57$ & $1.01 \pm 0.55$ & $0.88 \pm 0.48$ \\
$\begin{array}{l}\text { The number of } \\
\text { blown nose }\end{array}$ & LH2171 & 48 & $0.95 \pm 0.63$ & $0.87 \pm 0.70$ & $0.87 \pm 0.72$ & $0.91 \pm 0.78$ & $0.87 \pm 0.77$ \\
& Placebo & 46 & $1.06 \pm 0.65$ & $0.98 \pm 0.68$ & $1.04 \pm 0.79$ & $1.16 \pm 0.84$ & $1.15 \pm 0.80$ \\
$\begin{array}{l}\text { Nasal } \\
\text { obstruction }\end{array}$ & LH2171 & 48 & $0.87 \pm 0.69$ & $0.77 \pm 0.61$ & $0.78 \pm 0.73$ & $0.70 \pm 0.74^{*}$ & $0.64 \pm 0.61^{*}$ \\
& Placebo & 46 & $1.01 \pm 0.78$ & $0.98 \pm 0.75$ & $0.99 \pm 0.73$ & $0.97 \pm 0.78$ & $0.91 \pm 0.71$ \\
LH2171 & 48 & $1.32 \pm 0.74$ & $0.95 \pm 0.66^{* *}$ & $0.85 \pm 0.68^{* * *}$ & $0.72 \pm 0.64^{* * *}$ & $0.62 \pm 0.54^{* * *}$ \\
Nose itching & Placebo & 46 & $1.25 \pm 0.86$ & $1.09 \pm 0.78$ & $0.94 \pm 0.70^{* *}$ & $0.90 \pm 0.73^{*}$ & $0.75 \pm 0.61^{* * *}$
\end{tabular}




\begin{tabular}{|c|c|c|c|c|c|c|c|}
\hline \multirow{2}{*}{ Eye itching } & LH2171 & 48 & $1.25 \pm 0.86$ & $0.95 \pm 0.73^{\text {*** }}$ & $0.81 \pm 0.68^{* * *}$ & $0.76 \pm 0.79^{* * * *}$ & $0.59 \pm 0.65^{* * *}$ \\
\hline & Placebo & 46 & $1.23 \pm 0.82$ & $0.96 \pm 0.82^{*}$ & $0.84 \pm 0.77^{* *}$ & $0.87 \pm 0.76^{* *}$ & $0.72 \pm 0.68^{* * * *}$ \\
\hline \multirow{2}{*}{ Tearing } & LH2171 & 48 & $0.79 \pm 0.77$ & $0.59 \pm 0.63^{*}$ & $0.52 \pm 0.58^{*}$ & $0.46 \pm 0.62^{* *}$ & $0.36 \pm 0.49^{* * *}$ \\
\hline & Placebo & 46 & $0.77 \pm 0.64$ & $0.65 \pm 0.73$ & $0.56 \pm 0.65^{* *}$ & $0.54 \pm 0.58^{* *}$ & $0.52 \pm 0.61^{* *}$ \\
\hline \multirow{2}{*}{$\begin{array}{l}\text { Normal } \\
\text { activity }\end{array}$} & LH2171 & 48 & $0.85 \pm 0.56$ & $0.79 \pm 0.61$ & $0.73 \pm 0.62$ & $0.61 \pm 0.60^{* *}$ & $0.54 \pm 0.51^{* * *}$ \\
\hline & Placebo & 46 & $0.87 \pm 0.79$ & $0.83 \pm 0.71$ & $0.78 \pm 0.73$ & $0.77 \pm 0.69$ & $0.73 \pm 0.64$ \\
\hline
\end{tabular}

Data are expressed as the mean \pm standard deviation. ${ }^{\#} P<0.05$, ${ }^{\# \#} P<0.01$ between the groups by Man-Whitney $U$ test. $* P<0.05$, $* * P<0.01, * * * P<0.001$ compared to the baseline by the Wilcoxon signed rank test.

\section{Total IgE and antigen-specific IgE levels}

There were no significant differences between LH2171 group and P group in total and antigen-specific IgE levels at any of the experimental points (Table 8).

Table 8: $\operatorname{IgE}$ and specific $\operatorname{IgE}$ in serum in study 1.

\begin{tabular}{lllll}
\hline Items & Group & $\mathrm{n}$ & \multicolumn{2}{l}{ Change value from week 0 } \\
\cline { 4 - 5 } & LH2171 & 48 & $0.01 \pm 0.11$ & week 12 \\
\hline Total $\operatorname{IgE}(\log (\mathrm{IU} / \mathrm{mL}))$ & Placebo & 46 & $0.00 \pm 0.06$ & $0.04 \pm 0.13$ \\
& LH2171 & 48 & $0.05 \pm 0.10$ & $0.04 \pm 0.11$ \\
$\begin{array}{l}\text { Specific } \operatorname{IgE}(\log (\mathrm{IU} / \mathrm{mL})) \\
\text { (house dust } 1)\end{array}$ & Placebo & 46 & $0.02 \pm 0.09$ & $0.02 \pm 0.11$ \\
$\begin{array}{l}\text { Specific IgE }(\log (\mathrm{IU} / \mathrm{mL})) \\
(\text { mite })\end{array}$ & LH2171 & 48 & $0.04 \pm 0.09$ & $0.04 \pm 0.11$ \\
& Placebo & 46 & $0.03 \pm 0.08$ & $0.03 \pm 0.10$ \\
\hline
\end{tabular}

\section{Adverse events}

Although several complaints of subjective symptoms were recorded during the study, all symptoms were mild except for a left-hand fracture with one subject. Thus, there were no serious adverse events. Additionally, there were no side effects related to the study food as judged by the responsible physician.

\section{Study 2}

\section{Subjects}

The study outline is shown in Figure 2. Among the people who provided written informed consent $(n=56), 20$ subjects were selected by our screening procedure. The characteristics of the 
subjects are shown in Table 9. A total of 20 subjects (9 males and 11 females; mean age $40.8 \pm$ 12.4 years) were screened for this study. We selected 10 subjects that tested negative for specific IgE antibodies against house dust and mites (4 males and 6 females). 10 subjects that manifested with nasal and ocular discomfort and tested positive for specific $\operatorname{IgE}$ antibodies against house dust and mites (5 males and 5 females) (Table 9). No subject deviated from the protocol during the study period. Thus, data from all 20 subjects were included in the analysis.

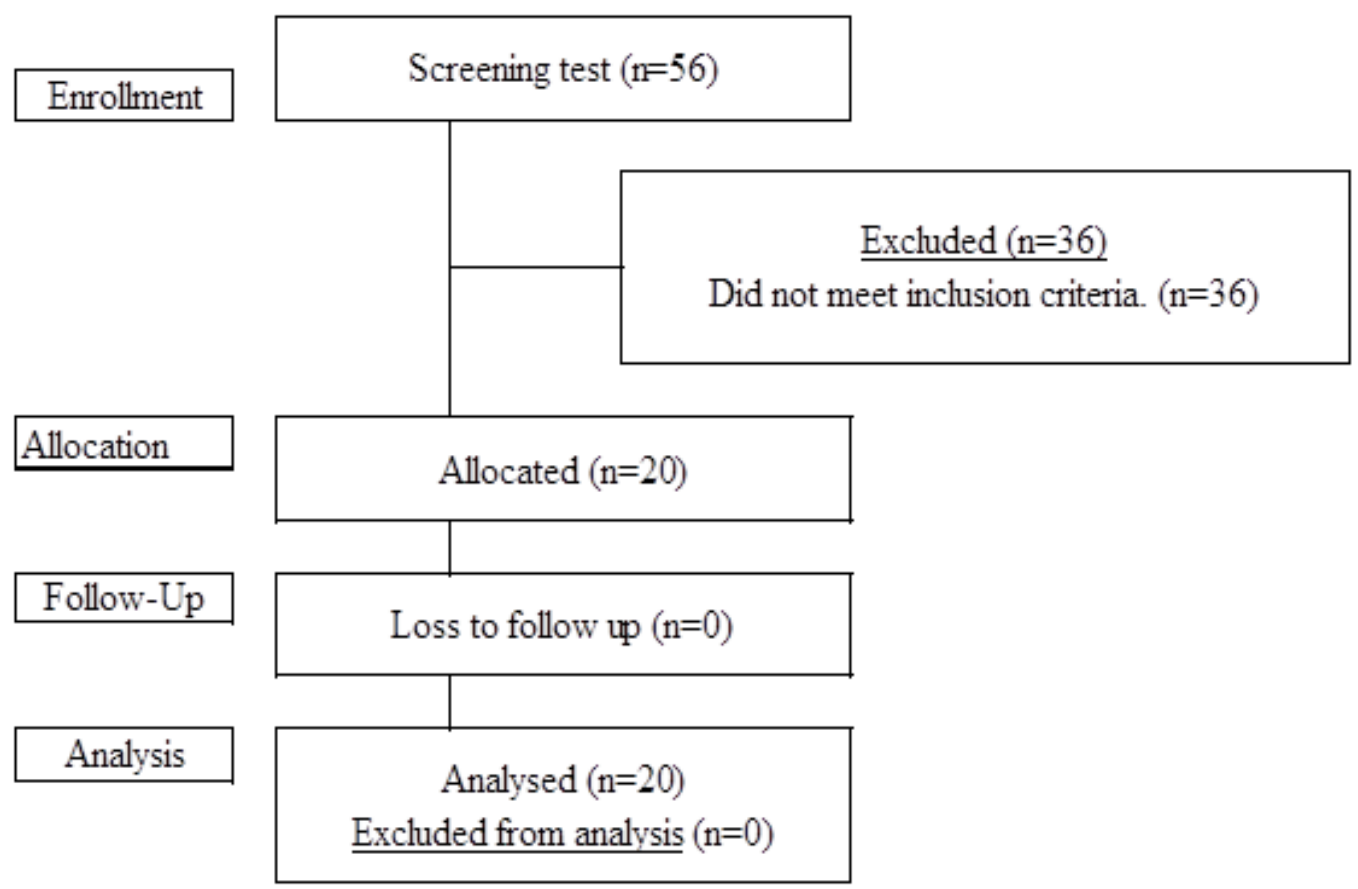

Figure 2. Flow diagram for study 2

Table 9: Characteristics of the subjects at allocation in study 2.

\begin{tabular}{ccccc}
\hline Items & Unit & total & Male & Female \\
\hline $\mathrm{n}$ & & 20 & 9 & 11 \\
Age & & $40.8 \pm 12.4$ & $40.6 \pm 10.0$ & $41.0 \pm 14.5$ \\
Height & $\mathrm{cm}$ & $164.4 \pm 8.4$ & $171.5 \pm 6.0$ & $158.5 \pm 4.7$ \\
Weight & $\mathrm{kg}$ & $62.1 \pm 13.6$ & $73.1 \pm 11.4$ & $53.0 \pm 7.0$ \\
BMI & $\mathrm{kg} / \mathrm{m}^{2}$ & $22.9 \pm 4.1$ & $24.9 \pm 4.4$ & $21.2 \pm 3.1$
\end{tabular}




$\begin{array}{ccccc}\text { Systolic blood pressure } & \mathrm{mmHg} & 114.4 \pm 11.8 & 119.9 \pm 9.4 & 109.8 \pm 12.0 \\ \text { Diastolic blood pressure } & \mathrm{mmHg} & 69.0 \pm 8.5 & 71.9 \pm 8.9 & 66.5 \pm 7.6 \\ \text { Pulse rate } & \text { beat/min } & 69.6 \pm 10.3 & 69.3 \pm 14.9 & 69.8 \pm 5.0 \\ \text { House dust specific IgE } & \mathrm{UA} / \mathrm{mL} & 4.82 \pm 7.88 & 5.78 \pm 9.74 & 4.04 \pm 6.35 \\ \text { Mite specific IgE } & \mathrm{UA} / \mathrm{mL} & 6.05 \pm 9.78 & 6.78 \pm 11.31 & 5.46 \pm 8.86\end{array}$

Values are expressed as the mean \pm standard deviation.

\section{Adverse events}

During this study, 10 adverse events, namely soft stool, diarrhoea, constipation, gastroenteritis, stomach discomfort, cold symptoms (sore throat, runny nose, sneezing, malaise, and coughing), runny nose with sneezing, stuffy nose, and eye aches were reported in six subjects. However, their symptoms were transitory and mild. The subjects recovered without discontinuing taking the study food and did not require any additional treatment. There were no side effects related to the study food as judged by the responsible physician.

\section{Anthropometric measurements}

Changes in body weight, BMI, SBP, DBP, and pulse rate are shown in Table 10. There were several slight but significant changes of the anthropometric parameters during the treatment period compared to the values at the baseline. Body weight and BMI significantly increased on weeks 2, 4, and 6 compared to baseline. SBP values on week 2 were significantly lower, while DBP values were significantly higher on weeks 4 and 6 compared to baseline.

Table 10: Anthropometric measurement in study 2.

\begin{tabular}{|c|c|c|c|c|c|c|c|c|c|c|c|}
\hline \multirow{2}{*}{$\begin{array}{l}\text { Items } \\
\text { Weight }\end{array}$} & \multirow{2}{*}{$\begin{array}{l}\text { Unit } \\
\mathrm{kg}\end{array}$} & \multicolumn{3}{|c|}{ baseline } & \multicolumn{2}{|c|}{ week 2} & \multicolumn{2}{|c|}{ week 4} & \multicolumn{3}{|c|}{$\begin{array}{l}\text { week } 6 \\
\text { (after treatment) }\end{array}$} \\
\hline & & 62.06 & \pm & 13.62 & 62.72 & $\pm 13.61^{*}$ & 62.92 & $\pm 13.78^{* *}$ & 62.87 & \pm & $13.70^{* *}$ \\
\hline BMI & $\mathrm{kg} / \mathrm{m}^{2}$ & 22.85 & \pm & 4.11 & 23.09 & $\pm 4.01^{*}$ & 23.16 & $\pm 4.11^{* *}$ & 23.15 & \pm & $4.10^{* *}$ \\
\hline $\begin{array}{l}\text { Systolic blood } \\
\text { pressure }\end{array}$ & $\mathrm{mmHg}$ & 114.4 & \pm & 11.8 & 110.8 & $\pm 12.7^{*}$ & 114.1 & \pm 13.3 & 115.9 & \pm & 11.0 \\
\hline $\begin{array}{l}\text { Diastolic } \\
\text { blood pressure }\end{array}$ & $\mathrm{mmHg}$ & 69.0 & \pm & 8.5 & 69.7 & \pm 11.0 & 74.5 & $\pm 9.2^{* *}$ & 73.3 & \pm & $9.0^{* *}$ \\
\hline Pulse rate & beat $/ \mathrm{min}$ & 69.6 & \pm & 10.3 & 73.3 & \pm 14.1 & 69.6 & \pm 12.3 & 73.1 & \pm & 14.5 \\
\hline
\end{tabular}


Blood analysis, urinalysis, and total safety degree

Changes of blood test parameters are shown in Table 11. Although significant changes were observed between baseline and week 4 values, the mean values always remained within the optimum range. There were no significant changes from baseline to week 4 in the antigen-specific antibody serum titres in any of the subjects. The urinalysis parameters did not differ significantly at any time point. The physician determined that all subjects were safe during the study.

Table 11: Hematological and biochemical data in study 2 .

\begin{tabular}{|c|c|c|c|c|}
\hline Items & baseline & week 2 & week 4 & $\begin{array}{l}\text { week } 6 \\
\text { (after treatment) }\end{array}$ \\
\hline WBC (number/ $\mu \mathrm{L}$ ) & $5070.0 \pm 1210.1$ & $\begin{array}{l}5700.0 \pm \\
1592.7^{* *}\end{array}$ & $5545.0 \pm 1399.4$ & $5495.0 \pm 1332.4$ \\
\hline RBC (number $\times 10^{4} / \mu \mathrm{L}$ ) & $471.9 \pm 52.0$ & $474.6 \pm 51.0$ & $482.4 \pm 52.3^{*}$ & $475.6 \pm 54.8$ \\
\hline Hemoglobin (g/dL) & $14.28 \pm 1.16$ & $14.57 \pm 1.24^{*}$ & $14.64 \pm 1.29^{*}$ & $14.53 \pm 1.43$ \\
\hline Hematocrit (\%) & $44.31 \pm 3.57$ & $44.36 \pm 3.44$ & $45.16 \pm 3.86$ & $44.04 \pm 3.96$ \\
\hline $\begin{array}{l}\text { Platelet } \\
\text { (number } \times 10^{4} / \mu \mathrm{L} \text { ) }\end{array}$ & $26.11 \pm 5.02$ & $26.92 \pm 4.89$ & $27.14 \pm 5.07$ & $27.01 \pm 5.30$ \\
\hline $\begin{array}{l}\text { House dust specific IgE } \\
(\mathrm{UA} / \mathrm{mL})\end{array}$ & $4.82 \pm 7.88$ & - & $5.64 \pm 9.26^{*}$ & - \\
\hline $\begin{array}{l}\text { Mite dust specific IgE } \\
\text { (UA/mL) }\end{array}$ & $6.05 \pm 9.78$ & - & $6.30 \pm 10.06$ & - \\
\hline $\mathrm{TP}(\mathrm{g} / \mathrm{dL})$ & $7.34 \pm 0.34$ & $7.17 \pm 0.32^{*}$ & $7.28 \pm 0.34$ & $7.23 \pm 0.36$ \\
\hline Alb (g/dL) & $4.46 \pm 0.30$ & $4.40 \pm 0.30$ & $4.51 \pm 0.30$ & $4.41 \pm 0.30$ \\
\hline $\operatorname{AST}(\mathrm{U} / \mathrm{L})$ & $21.0 \pm 6.7$ & $21.1 \pm 9.1$ & $22.6 \pm 9.7$ & $22.6 \pm 10.4$ \\
\hline ALT (U/L) & $21.8 \pm 15.7$ & $23.2 \pm 19.9$ & $25.3 \pm 19.4$ & $23.1 \pm 18.0$ \\
\hline $\mathrm{LD}(\mathrm{U} / \mathrm{L})$ & $153.5 \pm 30.2$ & $156.9 \pm 34.5$ & $159.4 \pm 31.5^{*}$ & $173.6 \pm 50.1^{*}$ \\
\hline $\operatorname{ALP}(\mathrm{U} / \mathrm{L})$ & $202.0 \pm 52.2$ & $208.5 \pm 55.6$ & $205.9 \pm 48.4$ & $205.4 \pm 55.0$ \\
\hline$\gamma-\mathrm{GT}(\mathrm{U} / \mathrm{L})$ & $31.4 \pm 29.3$ & $35.5 \pm 36.7$ & $33.9 \pm 31.3$ & $32.9 \pm 33.0$ \\
\hline $\mathrm{TB}(\mathrm{mg} / \mathrm{dL})$ & $0.81 \pm 0.34$ & $0.76 \pm 0.39$ & $0.78 \pm 0.24$ & $0.74 \pm 0.27$ \\
\hline $\mathrm{DB}(\mathrm{mg} / \mathrm{dL})$ & $0.13 \pm 0.07$ & $0.12 \pm 0.05$ & $0.12 \pm 0.05$ & $0.14 \pm 0.12$ \\
\hline IB (mg/dL) & $0.68 \pm 0.30$ & $0.64 \pm 0.35$ & $0.66 \pm 0.21$ & $0.60 \pm 0.27$ \\
\hline $\mathrm{Cr}(\mathrm{mg} / \mathrm{dL})$ & $0.780 \pm 0.113$ & $0.753 \pm 0.127^{*}$ & $0.769 \pm 0.129$ & $0.740 \pm 0.134$ \\
\hline UN (mg/dL) & $12.89 \pm 2.95$ & $13.63 \pm 2.20$ & $13.17 \pm 3.05$ & $13.18 \pm 2.29$ \\
\hline UA (mg/dL) & $5.42 \pm 1.46$ & $5.12 \pm 1.41^{*}$ & $5.14 \pm 1.33$ & $5.06 \pm 1.49$ \\
\hline
\end{tabular}




\begin{tabular}{lllll}
$\mathrm{TC}(\mathrm{mg} / \mathrm{dL})$ & $207.0 \pm 36.5$ & $211.8 \pm 41.4$ & $207.7 \pm 38.7$ & $211.5 \pm 46.0$ \\
HDL-C $(\mathrm{mg} / \mathrm{dL})$ & $67.5 \pm 20.8$ & $66.9 \pm 20.9$ & $67.1 \pm 18.7$ & $65.7 \pm 21.9$ \\
$\mathrm{LDL}-\mathrm{C}(\mathrm{mg} / \mathrm{dL})$ & $112.8 \pm 35.4$ & $118.1 \pm 33.8$ & $114.4 \pm 30.8$ & $118.1 \pm 35.5$ \\
$\mathrm{TG}(\mathrm{mg} / \mathrm{dL})$ & $112.0 \pm 55.5$ & $153.1 \pm 176.6$ & $137.6 \pm 117.9$ & $211.8 \pm 459.4$ \\
$\mathrm{Na}(\mathrm{mEq} / \mathrm{L})$ & $141.2 \pm 1.5$ & $140.6 \pm 1.7$ & $140.6 \pm 2.3$ & $140.5 \pm 2.7$ \\
$\mathrm{~K}(\mathrm{mEq} / \mathrm{L})$ & $4.36 \pm 0.23$ & $4.44 \pm 0.31$ & $4.47 \pm 0.35$ & $4.49 \pm 0.35$ \\
$\mathrm{Cl}(\mathrm{mEq} / \mathrm{L})$ & $103.4 \pm 1.7$ & $103.1 \pm 1.7$ & $103.6 \pm 1.8$ & $103.9 \pm 2.7$ \\
$\mathrm{GLU}(\mathrm{mg} / \mathrm{dL})$ & $80.6 \pm 6.7$ & $84.3 \pm 6.6^{* *}$ & $82.4 \pm 11.0$ & $82.3 \pm 14.6$ \\
\hline
\end{tabular}

Values are mean \pm standard deviation. $* P<0.05, * * P<0.01$ compared to the baseline by the paired $t$-test.

\section{DISCUSSION}

In recent years, the increase in the prevalence of allergic diseases in Japan has become a significant social problem, especially because patients with perennial allergic rhinitis often become seriously asthmatic $[3,27,28]$. It is important to prevent the onset of allergic diseases while also developing the means of their pharmacological treatment. Given that prolonged drug treatment regimens may increase the risk of side effects, food products that prevent or improve resistance to allergies are an attractive option. Therefore, we evaluated the effects of LH2171, with mechanisms working through the suppression of the immune response, on perennial allergy symptoms.

The alleviating effect of LH2171 on the nasal and ocular discomfort was investigated in healthy Japanese subjects aged 20-64 years and who tested positive for IgE antibodies specific to house dust and/or mites. The subjects consumed DY containing LH2171 for 12 weeks by daily consecutive ingestion in a double-blind, placebo-controlled, parallel group comparative study. According to the QOL questionnaire, the decreases in the total scores of the nasal and ocular discomfort between week 0 and week 8 in LH2171 group were significantly larger than those in $\mathrm{P}$ group. In addition, the decreases of the nasal discomfort total score and nose itching score between week 0 and week 8 , which were side evaluation items of the nasal and ocular discomfort total score, were significantly larger in LH2171 group than in P group. The subjects' diaries revealed that the number of sneezes decreased significantly more on weeks 9-12 in LH2171 group than in $\mathrm{P}$ group. In addition, on weeks 12-16, the decreased frequency of the nasal discharges $(P=0.083)$ in LH2171 group tended to be lower than in P group. These findings indicated that the improvement effects due to the consumption of DY containing LH2171 likely produced a persistent effect lasting for at least 4 weeks after the termination of daily intake.

A significant difference was observed with the number of sneezes recorded in the diaries, but no significant difference was found in subjective symptoms based on the QOL questionnaire for sneezes. Therefore, these results suggested that a feeling such as a symptom in subjects might 
be harder to quantitate than concrete values. In the future, we plan to confirm the effect of LH2171 by conducting a more accurate study based on the present results.

The immediate reactions, including sneezing, rhinorrhoea, and eye symptoms, are observed during early contact with the sensitizing allergen, are induced by the IgE-dependent activation of mast cells, which subsequently release inflammatory substances, such as histamine, stored in intracellular granules. The late inflammatory reactions, such as itchy nose, occur several hours after the contact with the allergen and are associated with tissue damage accompanied by the infiltration of eosinophils and T lymphocytes into the tissue [29]. As LH2171 suppressed both the immediate reactions and late inflammatory reactions, it may have influenced several different pathways.

LAB has often been reported to suppress allergic symptoms by reducing antigen-specific IgE levels via the improvement of the Th1/Th2 cytokine balance [30]. We used LH2171 because in our previous study, this strain showed significant immunomodulatory effects, including the suppression of proliferation and inflammatory cytokine production in lipopolysaccharide-stimulated murine immune cells [24]. In the present study, we expected that administration of $\mathrm{LH} 2171$ would reduce $\operatorname{IgE}$ in the blood with improvement of allergic symptoms. However, no significant differences were observed between the groups in the specific $\operatorname{IgE}$ (against house dust and mites) and total IgE levels. In general, blood IgE levels dramatically change in response to the amount of antigen exposure, in our artificial murine allergy model and in people with seasonal allergy in pollen season, IgE levels could rise sharply. However, in the case of perennial allergy because the subjects receive a constant mild level of stimulation by the antigen existing in the room, blood levels of antigen-specific antibodies may not change drastically even though intake of LH2171 was effective in alleviating allergy symptoms. Additionally, serum concentrations of IFN $\gamma$ and IL-13, the indicators of Th1 and Th2 immune responses, were below the detection limit in most sample measurements (data not shown). Accordingly, for this analysis we selected subjects with milder symptoms rather than patients with significant nasal and ocular discomfort.

Many studies have reported beneficial and alleviating effects of lactobacilli or bifidobacteria on allergic symptoms. In some of these reports, a significant reduction of $\operatorname{IgE}$ in serum was not observed in either animal models or humans [31-34]. The fermented milk prepared with $L$. acidophilus L-92 [31] and that with two probiotic strains (L. rhamnosus GG and L. gasseri TMC0356) [32] significantly alleviated the allergic symptoms of the subjects. However, $\operatorname{IgE}$ level in the blood was not significantly altered in these studies. Therefore, the association between the improvement of allergic symptoms and alterations of IgE levels remains unclear. Recently, the allergen-induced synthesis of IL-5, but not of $\operatorname{IgE}$, has been shown to be a key mechanism of symptomatic episodes of seasonal allergic rhinitis in sensitized individuals [34]. A rise in IL-5 level seems to be a clinical manifestation of seasonal allergic rhinitis caused by Japanese cedar pollen. 
In the present study, significant improvements in nose itching, eye itching, and tearing were observed after study food consumption compared to the state of these parameters before the treatment in both groups. These results may be because we used fermented milk not only as the basis of the evaluated diet but also as a placebo in this study. Fermented milk has been known to have various effects on the physical and mental functions relevant to human health [35, 36]. Additionally, production of various bioactive peptides, including those generated from milk protein during fermentation by some LAB with high protease activity, has been reported [37]. These reports suggest that the positive effects of treatment in both groups in our present study may be due to the function of either already known or previously unidentified bioactive peptides.

Wang et al. reported that the ingestion of fermented milk containing L. paracasei 33 improved the QOL of patients with perennial allergic rhinitis [38]. In this study, intake of LH2171 significantly improved the outdoor activity and sleep scores associated with the QOL, compared to the effects of placebo intake. These findings suggest that intake of DY containing LH2171 improved the QOL, which was also reflected in the reduction of nasal and ocular discomfort.

Regarding safety in study 1, all observed symptoms were mild except for the fracture of the left hand in one subject that occurred in the placebo group. Thus, there were no serious adverse events judged by the responsible physician. In study 2, the ingestion of DY containing LH2171 three times a day (equivalent of $3 \times 10^{9}$ total cells per day) had no negative effect on either subjects that tested positive or those who tested negative for $\operatorname{IgE}$ antibodies against house dust or mites. Therefore, there was no problem with the safety of the study formulation (DY containing LH2171).

\section{CONCLUSION}

Our studies demonstrated that daily intake of DY containing LH2171 was devoid of any adverse effects and significantly improved the nasal and ocular symptoms and QOL in the subjects with ocular and nasal discomfort who were seropositive for specific IgE antibodies against house dust and/or mites. Further studies are necessary to obtain additional evidence and to clarify the mechanism of the anti-allergic effect of LH2171.

List of Abbreviations: ALB, albumin; ALP, alkaline phosphatase; ALT, alanine transaminase; AST, aspartate aminotransferase; BMI, body mass index; Cre, creatinine; DB, direct bilirubin; DBP, diastolic blood pressure; DY, drinkable yogurt; GLU, glucose; $\gamma \mathrm{GTP}$, gamma-glutamyl-transpeptidase; HDL-C, high-density lipoprotein cholesterol; IB, internal bilirubin; IFN $\gamma$, interferon- $\gamma$; IL, interleukin; LAB, lactic acid bacteria; LD, lactate dehydrogenase; LDL-C, low-density lipoprotein cholesterol; LH2171, Lactobacillus helveticus SBT2171; QOL, quality of life; SBP, systolic blood pressure; TB, total bilirubin; TC, total cholesterol; TG, triglycerides; TP, total protein; UA, uric acid; UN; blood urea nitrogen. 
Authors' Contributions: M. Yamashita and T. Kabuki designed the study and wrote the initial draft of the manuscript. T. Enomoto also designed the study and contributed to analysis and interpretation of data. All other authors contributed to data collection and interpretation and critically reviewed the manuscript. All authors approved the final version of the manuscript and agree to be accountable for all aspects of the work and ensuring that questions related to the accuracy or integrity of any part of the work are appropriately investigated and resolved.

Competing Interests: MY, EK, SO, MI, KI, and TK are employees of Megmilk Snow Brand Co., Ltd.

Acknowledgments and Funding: We would like to thank Professor Tetsuro Yamamoto and his colleagues (Total Technological Consultant Co. Ltd., Tokyo, Japan) for helpful advice regarding the preparation of the manuscript and statistical expertise and Editage (www.editage.jp) for English language editing. These studies were funded by Megmilk Snow Brand Co., Ltd.

\section{REFERENCES}

1. Okubo K, Kurono Y, Fujieda S, Ogino S, Uchio E, Odajima H, Takenaka H, Baba K: Japanese Guideline for Allergic Rhinitis. Allergol Int 2011, 60: 171-189

2. Strachan DP: Hay fever, hygiene, and household size. BMJ 1989, 299: 1259-1260.

3. Okubo K, Kurono Y, Ichimura K, Enomoto T, Okamoto Y, Kawauchi H, Suzaki H, et al.: Japanese guidelines for allergic rhinitis 2017. Allergol Int 2017, 66: 205-219.

4. Simpson A, Simpson B, Custovic A, Cain G, Craven M, Woodcock A: Household characteristics and mite allergen levels in Manchester,UK. Clin Exp Allergy 2002, 32: 1413-1419.

5. Celedón JC, Milton DK, Ramsey CD, Litonjua AA, Ryan L, Platts-Mills TAE, Gold DR: Exposure to dust mite allergen and endotoxin in early life and asthma and atopy in childhood. J Allergy Clin Immunol 2007, 120: 144-149.

6. Okada H, Kuhn C, Feillet H, Bach J-F: The "hygiene hypothesis" for autoimmune and allergic diseases: an update. Clin Exp Immunol 2010, 160: 1-9.

7. Corren J, Busse W, Meltzer EO, Mansfield L, Bensch G, Fahrenholz J, Wenzel SE, et al.: A Randomized, Controlled, Phase 2 Study of AMG 317, an IL-4R $\alpha$ Antagonist, in Patients with Asthma. Am J Respir Crit Care Med 2010, 181: 788-796.

8. Elmadfa I, Klein P, Meyer AL: Immune-stimulating effects of lactic acid bacteria in vivo and in vitro. Proc Nutr Soc 2010, 69: 416-420.

9. George Kerry R, Patra JK, Gouda S, Park Y, Shin H-S, Das G: Benefaction of probiotics for human health: A review. J Food Drug Anal 2018, 26 :927-939.

10. Kalliomaki M, Isolauri E: Role of intestinal flora in the development of allergy. Curr Opin Allergy Clin Immunol 2003, 3: 15-20.

11. Mennini M, Dahdah L, Artesani MC, Fiocchi A, Martelli A: Probiotics in Asthma and Allergy Prevention. Front Pediatr 2017, 5: 165.

12. Tang R-B, Chang J-K, Chen H-L: Can probiotics be used to treat allergic diseases? J 
Chinese Med Assoc 2015, 78: 154-157.

13. Cuello-Garcia CA, Brozek JL, Fiocchi A, Pawankar R, Yepes-Nuñez JJ, Terracciano L, Gandhi S, et al.: Probiotics for the prevention of allergy: A systematic review and meta-analysis of randomized controlled trials. J Allergy Clin Immunol 2015, 136: 952-961.

14. Yamamoto K, Yokoyama K, Matsukawa T, Kato S, Kato S, Yamada K, Hirota T: Efficacy of prolonged ingestion of Lactobacillus acidophilus L-92 in adult patients with atopic dermatitis. J Dairy Sci 2016, 99(7): 5039-5046.

15. Shida K, Takahashi R, Iwadate E, Takamizawa K, Yasui H, Sato T, Habu S, et al.: Lactobacillus casei strain Shirota suppresses serum immunoglobulin $\mathrm{E}$ and immunoglobulin G1 responses and systemic anaphylaxis in a food allergy model. Clin Exp Allergy 2002, 32: 563-570.

16. Ivory K, Chambers SJ, Pin C, Prieto E, Arqués JL, Nicoletti C: Oral delivery of Lactobacillus casei Shirota modifies allergen-induced immune responses in allergic rhinitis. Clin Exp Allergy 2008, 38: 1282-1289.

17. Fortina, Nicastro, Carminati, Neviani, Manachini: Lactobacillus helveticus heterogeneity in natural cheese starters: the diversity in phenotypic characteristics. J Appl Microbiol 1998, 84: 72-80.

18. European Food Safety Authority (EFSA): Opinion of the scientific committee on a request from EFSA on the introduction of a qualified presumption of safety (QPS) approach for assessment of selected microorganisms referred to EFSA. EFSA J 2007, 587: e16.

19. Rossetti L, Carminati D, Zago M, Giraffa G: A Qualified Presumption of Safety approach for the safety assessment of Grana Padano whey starters. Int J Food Microbiol 2009, 130(1): 70-73.

20. Guglielmetti S, Taverniti V, Minuzzo M, Arioli S, Zanoni I, Stuknyte M, Granucci F, et al.: A dairy bacterium displays in vitro probiotic properties for the pharyngeal mucosa by antagonizing group A Streptococci and modulating the immune response. Infect Immun 2010, 78: 4734-4743.

21. Taverniti V, Guglielmetti S: Health-Promoting Properties of Lactobacillus helveticus. Front Microbiol 2012, 3: 392.

22. Skrzypczak K, Gustaw W, Wasko A: Health-promoting properties exhibited by Lactobacillus helveticus strains. Acta Biochim Pol 2015, 62: 713-720.

23. Sasaki M, Bosman BW, Tan PST: A new, broad-substrate-specificity aminopeptidase from the dairy organism Lactobacillus helveticus SBT 2171. Microbiology 1996, 142: 799-808.

24. Yamashita M, Ukibe K, Uenishi H, Hosoya T, Sakai F, Kadooka Y: Lactobacillus helveticus SBT2171, a cheese starter, regulates proliferation and cytokine production of immune cells. J Dairy Sci 2014, 97(8): 4772-4779.

25. Hosoya T, Sakai F, Yamashita M, Shiozaki T, Endo T, Ukibe K, Uenishi H, et al.: Lactobacillus helveticus SBT2171 inhibits lymphocyte proliferation by regulation of the JNK signaling pathway. PLoS One 2014, 9(9): e108360. 
26. Yamashita M, Matsumoto K, Endo T, Ukibe K, Hosoya T, Matsubara Y, Nakagawa H, et al.: Preventive Effect of Lactobacillus helveticus SBT2171 on Collagen-Induced Arthritis in Mice. Front Microbiol 2017, 8: 1159

27. D'Amato G, Holgate ST, Pawankar R, Ledford DK, Cecchi L, Al-Ahmad M, et al.: Meteorological conditions, climate change, new emerging factors, and asthma and related allergic disorders. A statement of the World Allergy Organization. World Allergy Organ J 2015, 8: 1-52.

28. Yamada T, Saito H, Fujieda S: Present state of Japanese cedar pollinosis: the national affliction. J Allergy Clin Immunol 2014, 133: 632-639.e5.

29. Konishi E, Uehara K: Distribution of Dermatophagoides mite (Acari: Pyroglyphidae) antigens in homes of allergic patients in Japan. Exp Appl Acarol 1995, 19: 275-286.

30. Ozdemir, O: Various effects of different probiotic strains in allergic disorders: an updata from laborator and clinical data. Clin Exp Immunol 2010, 160: 295-304.

31. Ishida Y, Nakamura F, Kanzato H, Sawada D, Yamatomo N, Kkagata H, Oh-ida M, et al.: Effect of Milk Fermented with Lactobacillus acidophilus strain L-92 on symptoms of Japanese cedar pollen allergy: A randomized placebo-controlled trial. Biosci Biotechnol Biochem 2005, 69: 1652-1660.

32. Kawase M, He F, Kubota A, Hiramatsu M, Saito H, Ishii T, Yasueda H, et al.: Effect of fermented milk prepared with two probiotic strains on Japanese cedar pollinosis in a double-blind placebo-controlled clinical study. Int J Food Microbiol 2009, 128(3): 429-434.

33. Kawase M, He F, Kubota A, Harata G, Hiramatsu M: Orally administrated Lactobacillus gasseri TMC0356 and Lactobacillus GG alleviated nasal blockage of guinea pig with allergic rhinitis. Microbiol Immunol 2007, 51: 1109-1114.

34. Ohashi Y, Nakai Y, Tanaka A, Kakinoki Y, Masamoto T, Kato A, Washio Y, et al.: Allergen-induced synthesis of interleukin-5, but not of $\mathrm{IgE}$, is a key mechanism linked to symptomatic episodes of seasonal allergic rhinitis in sensitized individuals. Scand J Immunol 1998, 47: 596-602.

35. Meydani SN, Woel-kyu H: Immunologic Effects of Yogurt 1-4. Am J Clin Nutr 2000: 891-901.

36. Cross ML, Stevenson LM, Gill HS: Anti-allergy properties of fermented foods: An important immunoregulatory mechanism of lactic acid bacteria? Int Immunopharmacol 2001, 1: 891-901.

37. Park YW, Nam MS: Bioactive Peptides in Milk and Dairy Products: A Review. Korean J Food Sci Anim Resour 2015, 35: 831-840.

38. Wang MF, Lin HC, Wang YY, Hsu CH: Treatment of perennial allergic rhinitis with lactic acid bacteria. Pediatr Allergy Immunol 2004, 15: 152-158. 